\title{
Recent Research on Flexible Fixtures for Manufacturing Processes *
}

\author{
Otto Jan Bakker ${ }^{\dagger}$ Thomas N. Papastathis, Svetan M. Ratchev and Atanas A. Popov \\ Manufacturing Research Division, Faculty of Engineering, University of Nottingham, \\ University Park, Nottingham, NG7 2RD, UK
}

\begin{abstract}
Fixtures, are used to fixate, position and support workpieces, and form a crucial tool in manufacturing. Their performance influences the manufacturing (and assembly) process of a product. Furthermore, fixturing can form a significant portion of the needed investment and total process planning time for the manufacturing system. Many fixturing concepts, as contribution to increase the flexibility of the manufacturing system, are reported in the literature. The flexible fixturing designs can be classified into the following seven categories: modular fixtures, flexible pallet systems, sensor-based fixture design, phase-change based concepts, chuck-based concepts, pin-type array fixtures and automatically reconfigurable fixtures. It is observed that the more intelligent and automated fixturing systems are designed with the demands for automation in certain industries in mind. Furthermore, different fixturing solutions suit the engineering demands for different manufacturing areas, this means that for the foreseeable future all technologies will remain current. From the self-reconfigurable fixturing techniques a new fixturing capability is emerging: in process reconfigurability for the optimal placement of clamps and supports during the whole process time. These several concepts together with some recent patents are studied here. The paper concludes with some prospective research directions in the field of flexible fixturing.
\end{abstract}

Keywords: flexible fixtures, conformable fixtures, active fixturing systems, intelligent fixturing systems, adaptive fixturing, reconfigurable fixturing.

\section{INTRODUCTION}

The advent of computer numerically-controlled (CNC) machine tools and machining centres, in combination with the infiltration of information technologies and the advance of computer science in manufacturing environments, have triggered a paradigm shift from mass manufacturing to mass customisation. Modern manufacturing systems are called to produce large numbers of small-sized batches of different products, or different product variants, in a cost-efficient manner. At the same time, the quality of the product must be maintained high in order to remain competitive. The automotive manufacturing sector is perhaps the most prominent example of this trend, with some manufacturers offering such customisation abilities that each model can have more than 1000 different variants.

${ }^{*}$ The published manuscript is available at EurekaSelect via http://dx.doi.org/10.2174/2212797611306020003 (Recent Patents on Mechanical Engineering): Bakker OJ, Papastathis TN, Ratchev SM, Popov AA. Recent Research on Flexible Fixtures for Manufacturing Processes, Recent Pat Mech Eng 2013; 6(2): 107-121.

${ }^{\dagger}$ Address correspondence to this author at the Manufacturing Research Division, University of Nottingham, University Park Campus, Nottingham, NG7 2RD, UK; Tel: +44 (0)115 84 67683; Fax: +44 (0)115 95 13800; E-mail: ottojan.bakker@nottingham.ac.uk 
For contemporary manufacturing industries in order to be able to competitively output their final products and maintain a prominent position in the global market, they need to invest in flexibility and product quality. Flexibility is a measure of how responsive to changes a production environments really is. A series of flexibility characteristics, as described by [1], outline the behaviour that manufacturing environments need to display:

- Machine flexibility, the ease of making changes required to produce a given set of part types.

- Process flexibility, the ability to produce a given set of part types, possibly using different materials, in different ways.

- Product flexibility, the ability to change over to produce new (set of) products very economically and quickly.

- Routing flexibility, the ability to handle breakdowns and to continue producing a given set of part types.

- Volume flexibility, the ability to operate profitably at different production volumes.

- Expansion flexibility, the ability to expand the system easily and in a modular fashion.

- Operation flexibility, the ability for the manufacturing engineer to interchange the ordering of several operations for each part type to resolve manufacturing or logistical issues.

- Production flexibility, the universe of part types that the manufacturing system can produce.

On the other hand, increasing the quality of the made products requires the use of specialised equipment that ensures minimal deviation from the designed attributes. As a result of the above, research and development activities in the manufacturing sector have focused on investigating and developing technologies and equipment that constantly push the boundaries of flexibility and cycle times, whilst minimising production costs without the loss of quality of the end result. Fixtures are an integral part of manufacturing systems and, as such, they have received considerable research attention.

This paper reviews the research carried out for the development of flexible fixtures as can be found in the literature and in patents. A survey in the literature reveals that a large part of the research effort goes into computer-aided fixture design, as reviewed in References [2-12]; fixture design verification, discussions on which can be found in References [2, 7-9]; active fixturing [13]. Overviews of prior art regarding hardware concepts for (automatically) reconfigurable fixtures can be found in the following publications: $[2,7,10,14-16]$. In order to establish the requirements for flexible fixturing systems, the fixture design process is studied in Sec. 2. Subsequently the several flexible fixturing concepts are surveyed in Sec. 3. The conclusions from the review are given in Sec. 5. Finally, prospective future developments in the research for the development of flexible fixturing systems are discussed in Sec. 6.

\section{FIXTURE DESIGN FOR FLEXIBLE MANUFACTURING}

\subsection{Fixturing Fundamentals}

During machining and assembly operations workpieces are fixated by a workholder. This is called fixturing and the devices used for holding a part are called fixtures or workpiece holders. Therefore, fixtures have to fulfil the following three main functions $[7-9,17]$ : 
- locating (positioning of the part),

- holding (fixation of a part by clamping the part),

- supporting (prevention of elastic and plastic deformation).

Hence, fixtures have to locate the workpiece accurately, unambiguously and do so quickly and reliably; supply sufficient clamping force for rigid and stable workholding; prevent against the occurrence of damage of its locating reference points or planes, and provide strong, rigid and stable support against deformation; accommodate part accessibility, enable a quick and easy loading and unloading of the part; allow for easy disposal of coolant and chips; provide easy and safe handling for the fixture machinist; be durable and maintainable at low cost; be as "flexible" as possible with respect to number of different parts it can handle (universality), and to the slight variation in part dimensions which it should be able to accommodate for (adjustability).

Rong et al. [9], see Fig. (1), and Kang and Peng [6] have categorised fixture design in four stages: setup planning, fixture planning, fixture configuration design and fixture design verification. Note that other authors, such as [8], distinguish two separate stages within the "fixture configuration design". The first part of this review will be devoted to a discussion of the specifics regarding fixture designs. As Rong et al. [9] discuss the design of fixtures from a computer-aided design perspective, and this research has a different outlook, not all the bullet points shown in Fig. (1) will be discussed here in detail.

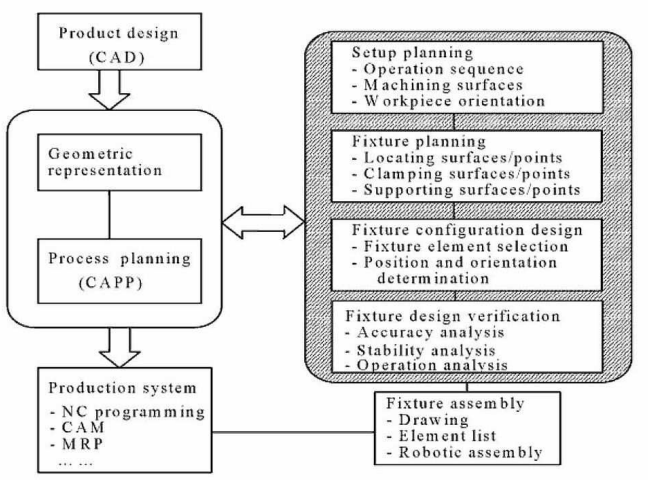

Fig. (1): A fixture design process-oriented flowchart. Source: Ref. [9], Fig. 2.2.

\subsection{Setup Planning}

One of the major complicating factors in fixture design in general is that fixturing is strongly a workpiece- and process-dependent part of the manufacturing chain. Already during product/part design the design engineer needs to address the issues regarding the manufacturability of the components. As seen in Fig. (1), during this stage of the fixture design the following questions need to be addressed:

1. In which orientation of the workpiece (surfaces) can most machining processes be executed?

2. In what order will the machining take place? 
Forming processes often require allowances, which result in poor locating of the part with respect to the fixture's reference frame and therefore cannot be used as geometrical reference points. This leads to the third question:

3. Are any specially designed reference points required?

Furthermore, at this stage a fundamental choice has to be made, based on the stiffness of the workpiece relative to the machining forces. In order to avoid a stack-up of tolerances, it is paramount that manufacturing operations are carried out in the same part-fixture setup [9, 17].

If the workpiece is relatively compliant, like e.g. turbine blades for aero-engines, it may be necessary to use non-conventional fixturing technologies, such as concepts based on phase-change materials or pin-type array fixtures [7]. A further discussion of flexible fixturing technology can be found in Sec. 3.

\subsection{Fixture Layout Synthesis}

The next stage in fixturing design is the fixture planning, as can be observed in Fig. (1). The order in which the fixture layout synthesis is executed is given in [8], Sec. 6.2.1 and Fig. 6.2. Firstly, locating points are to be selected during the fixture planning from the reference points and surfaces assigned for location during the setup planning. The validity of the locating scheme is verified with a kinematic restraint analysis on basis of the screw theory. The rigid body motion of the workpiece can be mapped onto a so-called screw, which means that the motion is decomposed into a rotation about an axis followed by a translation along that axis. In the screw theory, the twist represents the velocity of workpiece. Hence, if the all six degrees of freedom of the rigid part are properly constrained, the twist is zero [7-9, 18, 19].

Regarding the locator layout synthesis, the engineer can utilise the accumulated knowledge gained from previous fixture designs. For example, in case the position for the locating points is not restricted, it is best to place the locators far apart, as this minimises the reaction forces against applied machining moments. Or, fixture designs for parts from the same part family can be reused with only small changes. Knowledge based design has been the incentive of extensive research into the computer aided approaches of automatisation and optimisation of locator layouts using rule-based, expert systems and case-based methods [4-9].

Additional supports are placed on the basis of a deformation analysis. An overwhelming majority of research publications only consider static forces acting on the part, notable exceptions can be found in the papers by Daimon et al. [20] and Deiab [21], who take the dynamic mode shapes into account in a structural modification strategy to establish a support layout design. In certain cases, it can be very hard or impossible to place additional supports. In order to address this problem, Ceglarek and coworkers, e.g. [22], studied methods to achieve finite element analysis-based locator layout synthesis for sheet metal part handling or assembly fixtures.

Further down in fixture layout synthesis, suitable clamping locations are determined. Together, clamps and locators should provide form as well as force closure. Force closure is obtained when a given clamping force results in reaction forces at the locators that are pointed inward into the part. To fulfil the conditions for stable workholding, contact(s) between part and locators is required at all times, and the clamping force must be large enough to maintain force closure under any external loading of bounded magnitude. It is perceived that workpiece contact with locators:

- prevents the workpiece from moving (macro-slip) inside the fixture,

- minimises the vibrational workpiece displacement. 
Force closure and, of course, force and moment equilibrium are generally verified with (a modified version of) the screw theory, where the part is considered to be rigid, by calculating the "wrench". The wrench relates the force and torque acting on the workpiece in a similar way as the twist does for the motion. This is what is called the total restraint analysis by Nee et al. [8]. Only few examples can be found of studies where a flexible part is considered in the clamping force analysis. Force closure does not necessarily coincide with form closure, as force closure is a stricter condition than form closure $[8,19]$.

\subsection{Fixture Design Verification}

Fixture design verification, see Fig. (1), is traditionally the stage in which the fixture performance is analysed $[7,9,23]$.

\subsubsection{Fixture Performance}

The fixture performance is determined by the surface quality and dimensional errors the workpiece has, after all the machining processes planned for that specific part-fixture setup have been carried out. Fixture-related sources contributing to poor surface quality and tolerances can be sorted into the following categories: workpiece and fixture deformation due to clamping and machining forces, locating errors due to tolerances in the workpiece dimensions, locator placement and locator dimensions, poor workpiece positioning [24-28].

When a part has poor tolerances at the datum points, in some occasions, one is able to optimise the position and orientation of the workpiece by allowing for some adjustability of the locators, thus compensating for the workpiece-tolerance-induced locating errors. This compensation process can actually be automatised using sensor-based and automatically reconfigurable fixturing concepts, see Sec. 3 for a discussion of these concepts. Workpiece deformation due to external forces, which can originate from machining, gravitational or clamping, can be minimised by placing the locators such that the reaction forces, against an applied machining moment at the locators, are minimal. Additional supports can be placed to prevent excessive deflection. Furthermore, the applied clamping force should be as low as possible, to minimise the deformation of the fixtured part.

\subsubsection{Verification Analyses}

The verification of the fixture design is an important step in the design cycle, Rong et al. [9] and Nee et al. [7] devote the second half of their books on this issue, and Leopold [23] stresses its importance quite early in the introduction of his review paper. Fixture design verification usually consists of the following analyses:

- A tolerance sensitivity analysis - the designed position of the locators and their actual location differs due to tolerances. This can have a profound influence on the position and orientation of the part in the fixture. With a tolerance sensitivity analysis, one can determine this influence of the misplacement of the locators and calculate the allowable tolerances in the locator placement [29-31]. Automatically reconfigurable fixtures holding integrated position transducers should offer sufficient position resolution. Large fixtures, such as aircraft assembly fixtures are often constructed with the assistance of laser-tracker metrology. Wang [32] describes a procedure to measure fixturing error using CMMs (coordinate measurement machines). The recent strong advances of optical CMM (photogrammetry) [33] will probably further the use of CMMs for fixturing. 
- an accessibility analysis - studies the accessibility of the part for the machine tools, usually done by calculating the working envelope of the machine tools $[9,34]$, or by means of virtual reality simulation [35].

- A stability analysis - a more thorough analysis of the workholding stability, that verifies the existence of force closure as specified during the fixture layout synthesis. Analyses focus on friction force, minimum clamping forces, clamping sequences, workpiece and fixture deformation $[9,23]$.

\subsection{Requirements for a Flexible Fixturing System}

From the study of the design process one can establish the desired specifications for a fixturing system that can meet the demands for flexible use of manufacturing facilities. In general, fixtures will have to supply accurate location (locating), stiffness for support, sufficient clamping force and stable workholding. The main requirements can be listed as follows:

1. Low reconfiguration times.

2. Accurate locating.

3. Adjustability.

4. Capabilities for realigning and manipulation of the workpiece.

5. Reconfigurability of clamps and supports during the manufacturing process, this part of the fixture layout can be re-optimised during the process.

6. Active control of clamping forces, to minimise the deformation in the part-fixture system due to the clamping forces.

Requirements 1.-4. can be achieved mechanically/manually or automatically. In case these are achieved automatically, the flexible fixturing system is called an intelligent fixturing system. Requirements 5. and 6. are based on smart technologies and are specifically set for intelligent fixturing systems. Note that not all these requirements may be needed at the same time due to financial and/or part-specific constraints.

\section{FLEXIBLE FIXTURE CONCEPTS}

Serious scientific research effort has been undertaken to establish the underpinning science for the development of new fixturing technology for flexible manufacturing. This resulted in myriad of publications and patents of fixturing strategies and design concepts for workholding, regarding the fixture configuration design. Kleinwinkel et al. [28], Nee et al. [7] and Shirinzadeh [16] have undertaken the effort to categorise the concepts and the latter two References have summarised their findings in useful diagrams. These diagrams have been combined and the resulting diagram is shown in Fig. (2). The names for some of the strategies have been updated and some emerging concepts have been added. Furthermore, the concepts based on phase-change base technology have been classified on basis of fixturing concept, rather than on basis of the physics behind phase-change. This is actually already suggested in the taxonomy given in Ref. [7]. As can be seen in Fig. (2), seven basic fixturing concepts (and the generic category "other fixturing concepts") have been identified in Refs. [7, 16], which can 
then be further categorised. These basic fixturing concepts are studied in more detail in the following sections. A summary table, Tab. (1) can be found in Sec. 4.

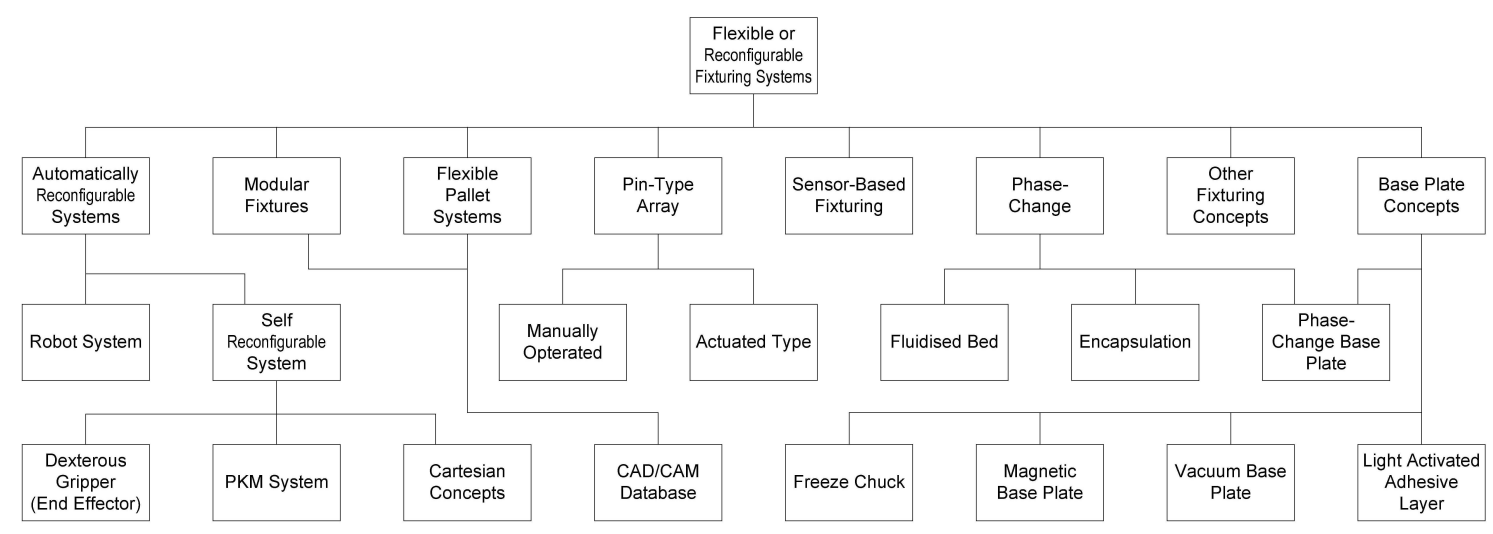

Fig. (2): Taxonomy of flexible fixturing concepts.

\subsection{Modular Fixtures}

Modular fixtures are constructed with standard elements and modular fixture elements. An example of a modular fixture is shown in Fig. (3). The fixture elements are easily connected by means of universal connection methods. There are two main concepts for universal connection methods: 'T-slots' and 'holes'. For this reason, the modular elements can best be described as adult versions of construction toys such as fishertechnik ${ }^{\circledR}$, LEGO ${ }^{\circledR}$ or MECCANO ${ }^{\circledR}$. Many approaches for computer-aided-design automatisation have been reported in the literature $[2,6,7,9,16]$.

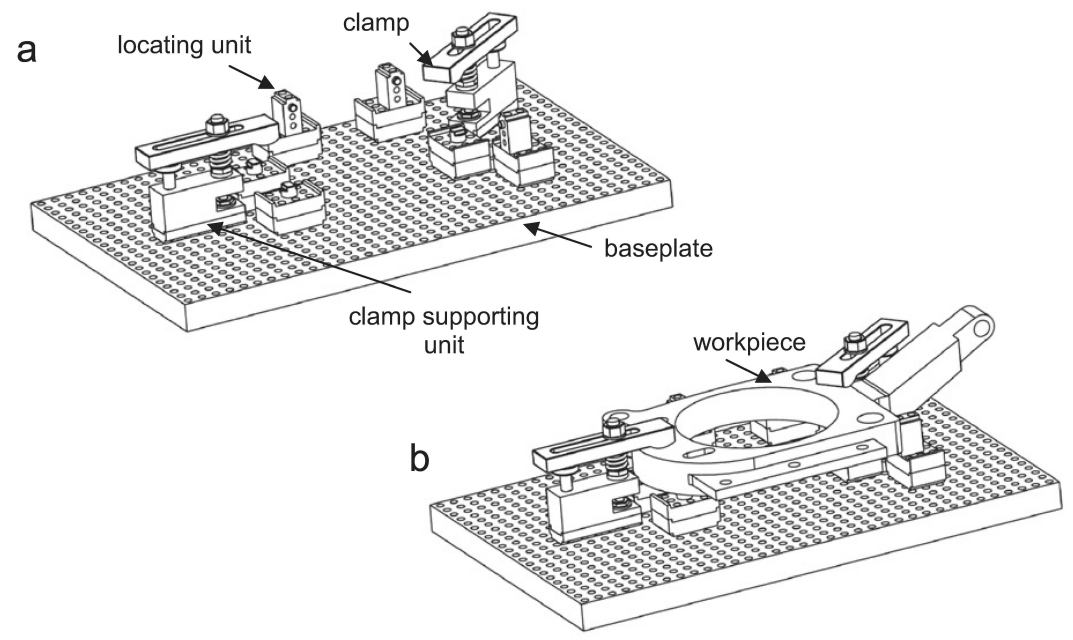

Fig. (3): Example of a modular fixture, (a) without part and (b) with part loaded. Source: Ref. [3, Fig. $1]$. 


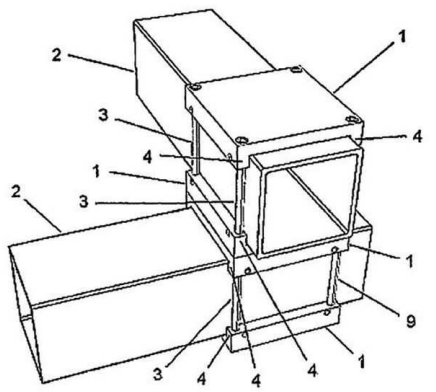

(a)

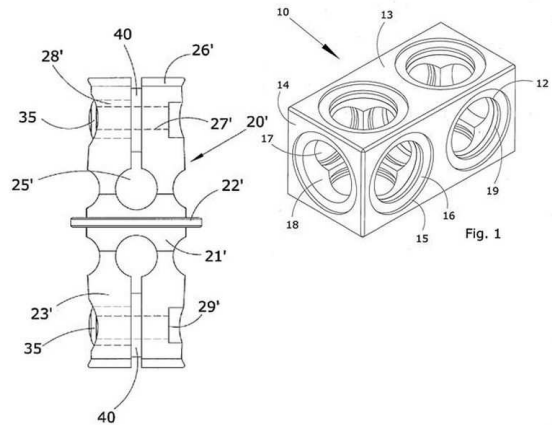

(d)

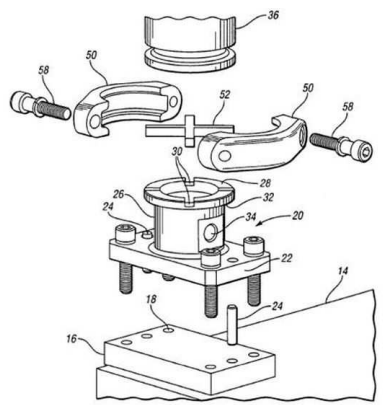

(b)

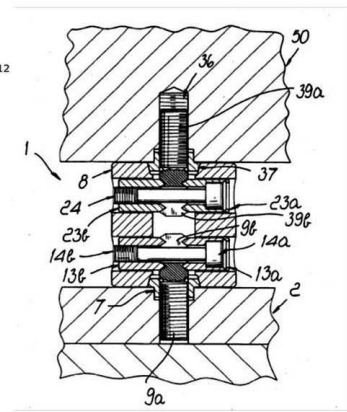

(e)
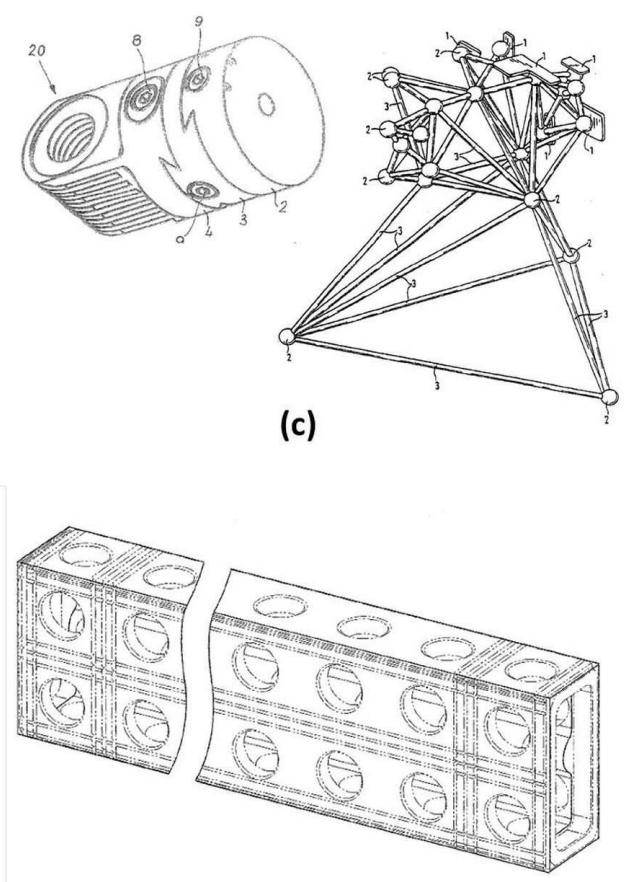

(f)

Fig. (4): Quick fastener systems: (a) Patent [36, Fig. 1], (b) Patent [37, Fig. 2], (c) Left Patent [38, Fig. 1] and right Patent [39, Fig. 1], (d) Patent [40, left: Fig. 6; and right: Fig. 1], (e) Patent [41, Fig. 3], (f) Patent [42, Fig. 1]. 
Assembly, tooling and or inspection fixtures fixtures are generally larger and less stiff than machining fixtures. Typically the modular elements utilised to build the fixture body are prismatic, hollow beam or tube shaped parts and connection elements to securely join these fixture body parts. A number of recent patents has been found for these connection elements. A number of patented connectors is shown in Fig. (4). Ossbahr [36] patented the connection shown in Fig. (4a). The plates and bolts assemblies are used as a connector between beams with a box-shaped cross-section. These beam-plate assemblies are then used as modular elements to build the frames of assembly, tooling or inspection fixtures. The established connection between the beams relies on friction and is not form-closed. External metrology devices can be employed to set the fixture frame to its prescribed tolerances. Patent [37] describes a fixturing system consists of booms with special flanges that are manufactured to tight tolerances. The booms and other pieces are interconnected by means of a collar and a cross-key that lock the flanges that are manufactured at the end of these booms and corner elements. The whole boom connection assembly can be found in Fig. (4b). Olssen et al. [38] made a patent application for an adapter device, which can be seen in Fig. (4c), left, for the precise positioning of locating elements or beams in a light-weight composite material-based fixturing system [39], shown in Fig. (4c), right. The patent filed in [40] describes a LEGO ${ }^{\circledR}$ TECHNIC-like joints to connect fixture elements. Unlike the LEGO ${ }^{\circledR}$ TECHNIC joints, the joint shown in Fig. (4d) is secured by bolts. The concept shown in Fig. (4e) and described in Reference [41] is a cylindrical implement that is used to connect two components, e.g. a locator to a fixture baseplate. Two eye bolts, numbered as parts $9 \mathrm{a}$ and $b$ and 39a and $b$ in Fig. (4e) are screwed in the vertical direction into the components, labelled as 2 and 50. Horizontally, two sets of two bushes, number 13a and b and 23a and b, are placed into the cylinder and secured with bolts 14 and 24. Marino [42] has patented the ornamental design for a grid bar used in a modular fixturing kit, shown in Fig. (4f). Two other patents in the area of modular assembly, tooling and inspection fixtures are Patent application [43], which describes a whole modular fixturing system based on extruded aluminium profiles, which resembles the fishertechnik ${ }^{\circledR}$ construction toys, and Patent [44], where a MECCANO ${ }^{\mathbb{R}}$-like element with a U-shaped cross-section is presented.

The perceived drawbacks of the modular fixturing concept are: the kits for modular fixture elements seem to be expensive, and locating accuracy in some cases is sub-standard, due to poor accuracy obtained during the assembly of the fixture, tolerances of the fixture elements and small relative displacements of the fixture elements during machining, and deterioration of the locating accuracy over time.

\subsection{Flexible Pallet Systems}

Assembled from the same elements as modular fixtures, flexible pallet systems are fixtures that are applied in big machines or multi-spindle stations and can handle multiple parts at a time [7]. The design for flexible pallet systems allows for individual loading and unloading of the workpiece. In recent years, several patent applications have been made for tombstone-based fixturing systems. An example is the patent by Ring et al. [45], which describes a modular tombstone equipped with tubing to accommodate for hydraulically actuated clamps, as shown in Figure (5).

\subsection{Fixturing Automation}

Recent years have also seen an increase in fixturing automation terms of actuated clamps and supports. Most of this work has a more applied than fundamental character and for this reason has not enjoyed much attention in academic publications. One of the main drives behind fixturing automation is the 


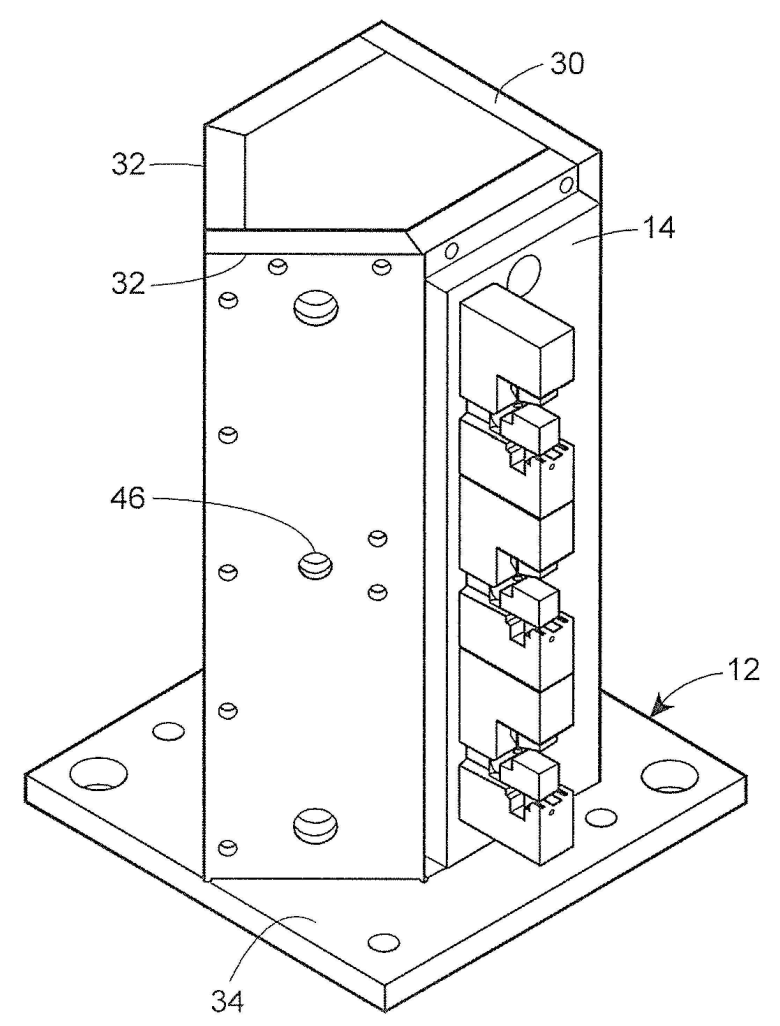

Fig. (5): Flexible pallet in tombstone configuration by Ring et al. [45, Fig. 3]. 
reduction of set-up times. Traditionally, parts are clamped by means of a screw mechanism. In order to speed up the clamping process, clamps with e.g. cam-action or toggle action have been developed and are commercially available. However, these clamps are still relying on manual operation. Manually operated systems are as good as the operator and are hence affected by the (in)experience, fatigue, strength and skills of the operator. Actuated clamps and supports, also known as power workholding overcomes these problems and offers realiable, consistent and repeatable operation. Additionally, power workholding systems offer are more benefits. Firstly, they are adjustable, clamping forces and work supports can easily be adjusted as required for each individual job. Secondly, these elements allow for further automation. Thirdly, the fixturing elements are actuated with an external power source: pneumatic, hydraulic, or electric, which allows the machinist or the automated system to operate these elements from a distance. Drawback, of course, is the increased costs of these elements. Typical elements found in the market and in the patents are swing clamps, e.g. Patent [46], clamp cylinders and work supports, e.g. Patent [47]. For instance, Stephens et al. [48] developed a hydraulic clamp cylinder which is driven by the spindle of a CNC machine tool. Ring et al. [45] developed a column that contains hydraulically actuated clamps. Similar to the system described by Patent [48], the hydraulic system is driven by the machine tool spindle. Another development are the zero-point clamps. These clamps were originally developed to quickly affix fixture base-plates to the machine tool and are widely commercially available. Similar to the lathe chuck, a zero-point clamp centres and clamps a nipple to its base. Each manufacturer has developed its own method for clamping the zeropoint nipples. Some recent examples of patents in this field are Patents $[49,50]$. Other applications for this type of clamp are being developed, e.g. Bakker et al. [51] apply zero-point clamps to located and fixate tooling holes in an aircraft assembly.

\subsection{Sensor-Based Fixture Design}

Sensor-based fixture design is a fixturing strategy where vision and sensor systems are utilised to ensure that the part is located correctly in the fixture (foolproofing). This is an important step towards the automatic loading into fixtures [9, 52]. Shirinzadeh [16] proposed to apply sensors and vision systems to establish the location and orientation of a part and to use this information to control the tooling operations in an assembly fixture.

\subsection{Phase-Change Based Concepts}

Phase-change based concepts rely on immobilising a workpiece by, apart from its machining areas, immersing it in a phase-change substance. After positioning the workpiece with an additional jig, the substance is solidified around the workpiece. The actual physics behind solidification depends on the substance that is used: pseudo-phase change material, low-melt alloy, bi-phase liquid, electro- and magneto-rheostatic liquids, etc..

Complex, fragile and flexible parts are encased into highly fixturable (easy-to-fixture) brickshaped parts and protected against possible damage caused by the fixture contacts. Nee et al. [7] distinguish between three different approaches. Fluidised bed: the container with phase-change liquid is the fixture itself. For instance, Zhang [53] patented a concept where a workpiece is initially located by headless set screws and subsequently secured container by a magneto-rheological fluid, as shown in Fig. (6). Encapsulation, in this strategy the part and the solidified liquid are taken out of the container and fixtured in an additional fixture. Phase-change baseplate, a concept where not the part, but the fixture elements are immersed in the phase-change liquid and the solidified fluid holds the fixture elements together. A related example is the pin-type array fixturing concept by Sears et 
al. [54] where the pins are secured by a magneto-rheological fluid, see Fig. (8a). The phase-change based concepts are highly flexible, but some specific drawbacks are associated with this technology. Typically, these special liquids are toxic, the retrieval of the workpiece from the solidified liquid may be a slow process, the energy demand for this technique is considerable and coolants and cutting fluids may diffuse into the solid, deteriorating the performance capacity of the special liquid [55].

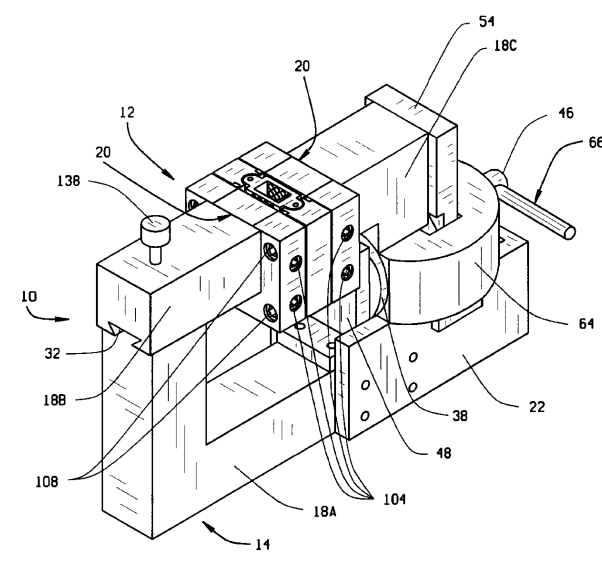

(a) Isometric projection of fixturing system. Source: Ref. [53], Fig. 1.

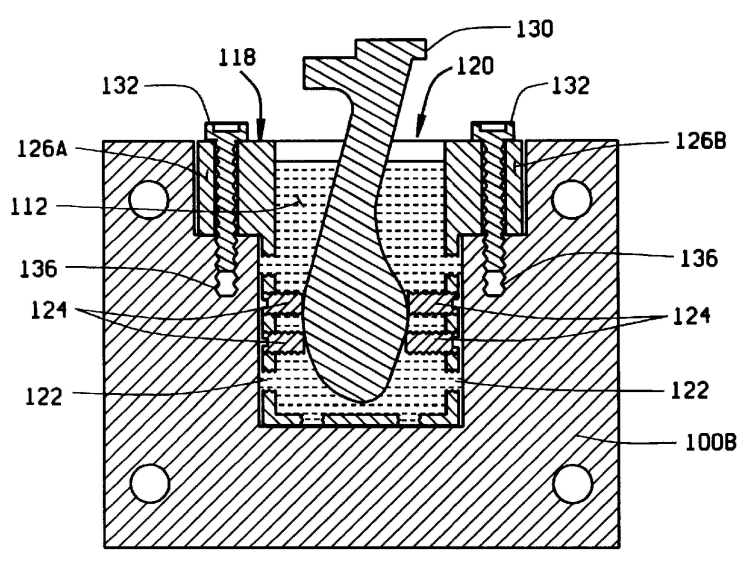

(b) Cross-section of actual workpiece holder. Source: Ref. [53] Fig. 7.

Fig. (6): Magneto-rheological-based fluidised bed fixture.

\subsection{Chuck-Based Concepts}

In case the machining forces are low and one of the sides of the workpiece is flat, it can be sufficient to fixture only the flat side with a chuck, whose self-holding capability relies on magnetic forces [16, $17,28]$, or vacuum forces $[17,28,56]$, or on the workpiece being frozen onto the chuck [28]. De Meter [57, 58] developed another principle to fasten a part onto a chuck. This concept is shown in Figure (7). This fixturing technology relies on the application of an UV-light activated adhesive layer on a chuck that fixates the part. To adjoin the part, the bond between fixture and part created by the adhesive layer is destroyed by a rod that can move in axial direction and or can rotate around its axis as can be seen in Figure (7b).

\subsection{Pin-Type Array Fixtures}

Pin-type array fixtures together with related concepts for reconfigurable tools and dies are based on a bed of pins. This type of fixtures differentiates itself from most of the other fixturing concepts as it does not follow the traditional 3-2-1 design paradigm, but the $n-2-1$ design paradigm. In some publications this type of fixtures is called 'conformable' or 'reconfigurable' fixtures. A mechanism inside the bed allows the tip of the individual pins to be positioned in axial direction, such that the surface of the tool is enveloped by the tips of the pins. Actuated and passive designs of this mechanism can be found in the literature $[59,60]$. Both designs shown in Fig. (8) are passive fixtures, i.e. there are no actuators that control the pins. In some designs the pins are only used to support-and-locate a workpiece, see e.g. Fig. (8a), a discussion of this type of designs is given in Refs. [7, 60]. A novel application of the this approach is found in the patent by Halford [61], where a bed of soft-pins can be set to approximate the desired contour and are subsequently machined to the required dimensional 


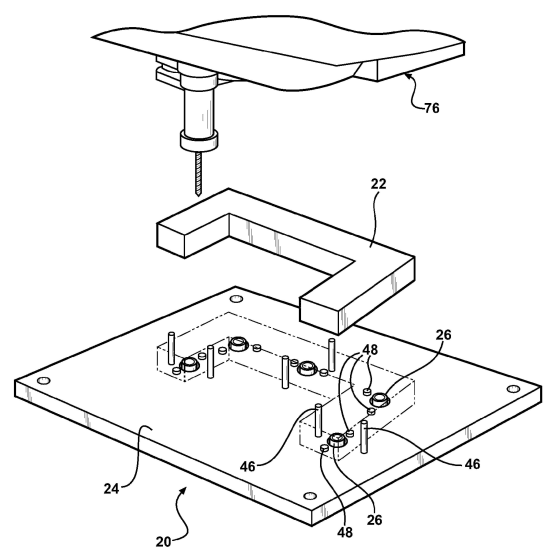

(a) Perspective view of fixturing system. Source: Ref. [58], Fig. 1.

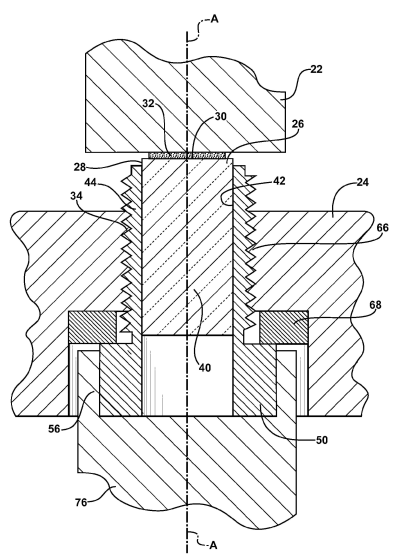

(b) Rod used breaking the adhesive bond between part and fixture. Source: Ref. [58] Fig. 4.

Fig. (7): Light actuated adhesive gripping chuck-based fixture.

precision. In other designs the pins are used to clamp the workpiece, see e.g. the fixture developed by Gindy et al. [63], shown in Fig. (8b). This fixture is used to clamp an air-foil from both sides and the pins are kept in position by a magneto-rheological fluid. Typically, an external jig is required to locate the part on the bed of pins. As seen in Fig. (8), pin spacing and dimensions can vary per application. This concept has not only been applied to the fixturing of turbine blades and sheet metal parts, but also to other (large) parts, such as engine blocks fixtured with pin-type arrays [14, 62].

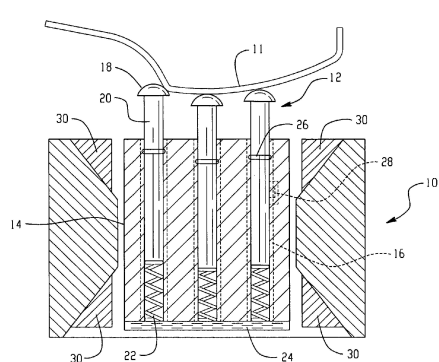

(a) Compliant part fixtured using a pin-type array fixture $N-2-1$ locating scheme. Source: Ref. [54], Fig. 1.

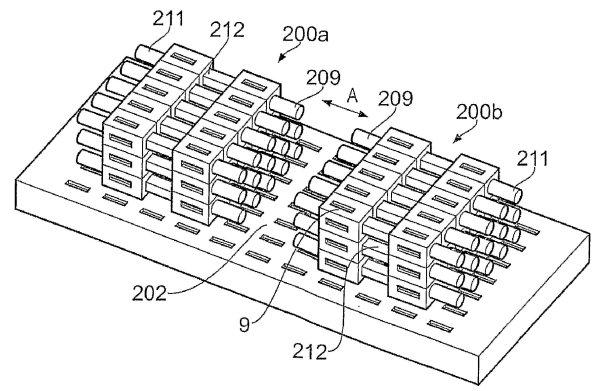

(b) Example of pin-type array fixture that is used for locating and clamping. Source: Ref. [63] Fig. 4.

Fig. (8): Examples of pin-type array fixtures.

\subsection{Automatically Reconfigurable Fixtures}

Five basic design strategies for automatically reconfigurable fixtures can be identified in literature. All these concepts rely on robots. Fixture modules can be assembled and reconfigured by means of robot systems, where a robot places the fixture elements in the holes of a base plate [52] or on magnetic chucks $[2,7,16]$. The lack of positional accuracy reported for modular fixtures is also 
reported for this concept, as it relies on the positional accuracy of the robot. Special attention deserves here the 'Automated Reconfigurable Machining Fixture' (ARMF) concept developed at the General Motors Research \& Development Center. This system is described by References [14, 46, 64-66]. The system consists of passive and actuated modular fixture elements that are placed on a magnetic chuck that acts as fixture base-plate, as shown in Fig. (9). In order to overcome the lack of positional accuracy of a robot, the fixture elements are placed on the base-plate by the CNC machine tool spindle with the aid of specially designed adapters. Additionally, the a nut-runner mounted on the spindle can be used to fasten or loosen any nuts if necessary and drive the actuated hydraulic elements, such as swing-clamps.

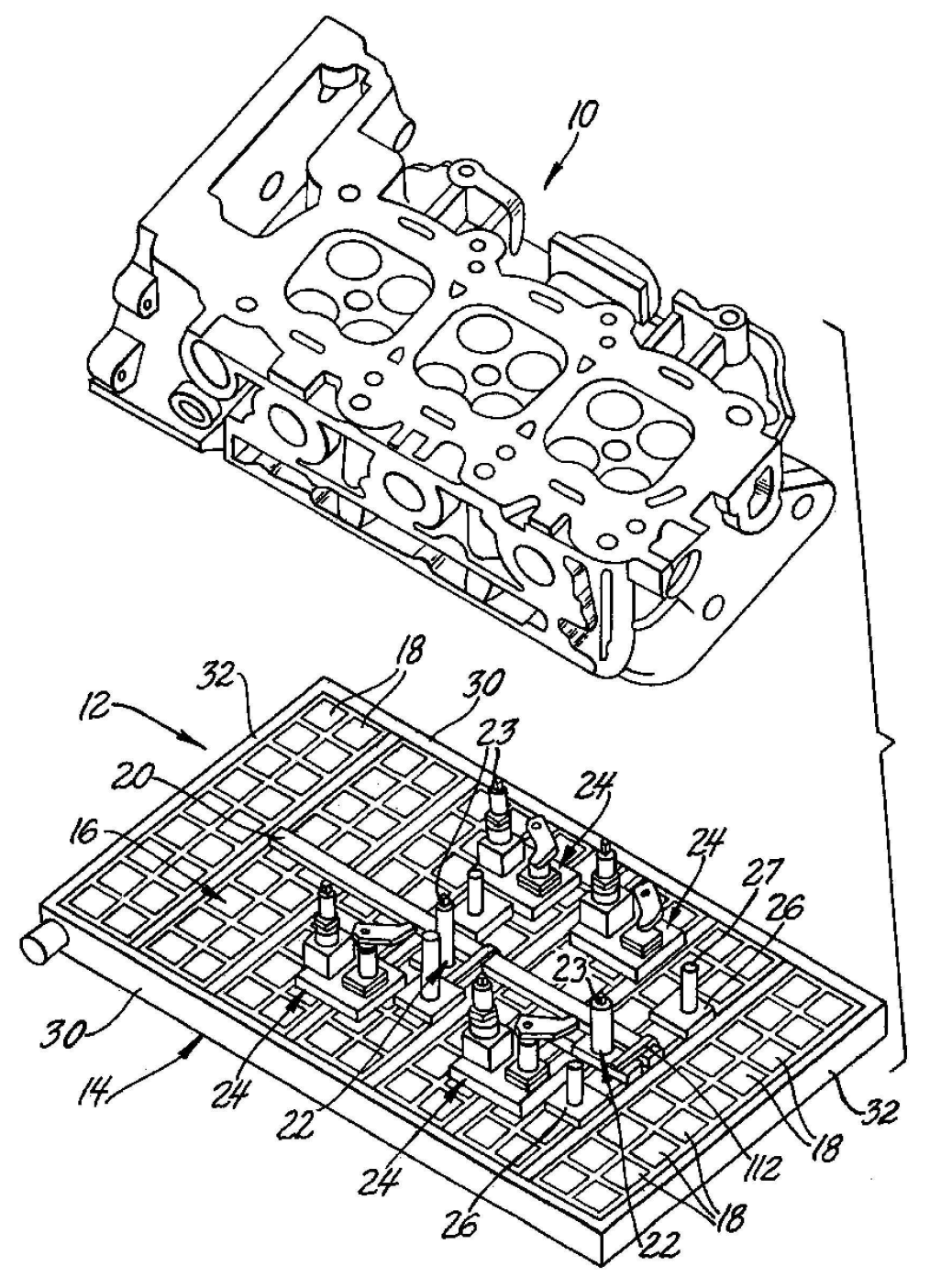

Fig. (9): Some fixture elements of the ARMF concept [65, Fig. 1].

Other strategies rely on the robot-as-fixture paradigm. The first of these concepts are the actuated pin-type array fixtures as described above. Secondly, concepts based on grippers that grasp objects are discussed in Ref. [7]. Often these designs are used in micro-machining and come under the name of "micro-manipulator" or "tweezers". The positional accuracy and load bearing capacity of 
dexterous grippers for larger object is generally lower than that of fixtures. For this reason, other gripping strategies have been proposed, e.g. the designs presented in Refs [67,68] where a part can be grasped, positioned and orientated. The remaining two fixturing concepts are robots in the form of parallel kinematic mechanisms (PMKs) and Cartesian coordinate robots. PKMs are mainly applied in assembly fixtures [69]. See e.g. Refs [70-72] for early applications of PKMs in fixturing. Recently, Jonsson et al. [73] developed the Affordable Reconfigurable Tooling (ART) concept where a fixture frame using box beams is build using the technology patented in Patent [36]. So-called Hexapods (Stewart platform) are placed on this frame providing locating points. The Hexapods can be set using external metrology. Currently, the Hexapods are set manually, however an externally actuated version is currently being developed at Linköping University. Other recent approaches can be found in Refs [14, 74]. Molfino et al. [75] propose the use of many PKMs (a swarm) to be able to relocate support points during the machining process. An illustration of this concept is shown in Fig. (10a), where a group of PKM-based fixture elements provides extra support at the tool location. PKMs can be positioned more accurately than Cartesian robots and have a proven capability to provide large stiffness, and they are often applied in modern machining centres [74, 76]. Another example is the Patent by Akeel [77], where automated Stewart platforms in combination with force sensors are utilised to obtain stress-free assemblies of body panels for the automotive industry. Cartesian robots, however, are easier to control and more compact than PKM-based robots. Design proposals involving Cartesian robots can be found in Tol [78] and Madden [79]. At The University of Nottingham, a more advanced version of Chan and Lin's multifinger modules [68] has been designed by the authors of Refs [80, 81]; their concept is shown in Fig. (10b). Clark [82] developed a manually reconfigurable fixture for woodworking comprising of horizontal hold down toggle clamps that can slide in a T-slot profile mounted on a base-plate. Some examples 3D Cartesian reconfigurable fixtures can be found. Kavanaugh [83] applied for a universal workholder. The concept is shown in Fig. (11a). This concept is intended to be used for hobbyists to fixture miniature models, for this reason the concept relies on rods, sliders and brakes, and is not automated. More advanced and automated 3D concepts of Cartesian robot based concepts have been developed for the assembly of cars at the body in white ${ }^{1}$ lines, e.g. [84, 85], the latter is shown in Fig. (11b). Related to the Cartesian coordinate design approach is the design of Du and Lin [86].

\subsection{Other Fixturing Concepts}

There are some other fixturing concepts that are developed and share certain aspects of flexible fixtures, but also have a dedicated character. Most of these are the so-called adaptive fixtures. A famous example of adaptive fixturing is described in References [87, 88] and Patent [89]. This fixture utilises a Coordinate Measurement Machine (CMM) to examine important features on automotive engine blocks. This information is used to identify the exact position and orientation of the surfaces to be machined. A micro-positioning base is applied to reposition the workpiece to its optimal location. Furthermore, Sturm et al. [90] developed actuated fixturing elements for an aerospace assembly fixture that can be used to realign sheet material during assembly and tooling.

Koczera [91, 92] developed a fixture which has shares some characteristics with modular fixtures and consists of a support column. Inside this support column there is a number of brackets that can used to fixture different parts and an expendable clamp.

\footnotetext{
${ }^{1}$ Body in White (BIW) refers to the stage in the production of cars in which the car body sheet metal (including doors, hoods, and deck lids) is assembled, but before the chassis, engine and trim (windshields, seats, upholstery, electronics, etc.) have been added to the assembly, or to the design of these sheet metal components.
} 


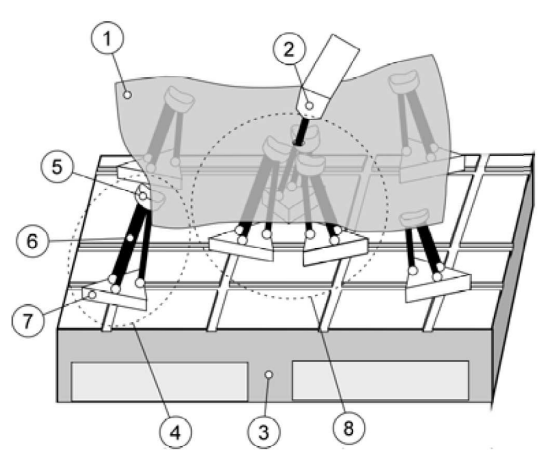

(a) "Conceptual schematic of self reconfigurable swarm fixture: (1) part; (2) manufacturing equipment; (3) bench; (4) agent; (5) support head; (6) positioning mechanism; (7) mobile bases; (8) concentration of agents in the manufacturing region." Source: Ref. [75], Fig. 2.

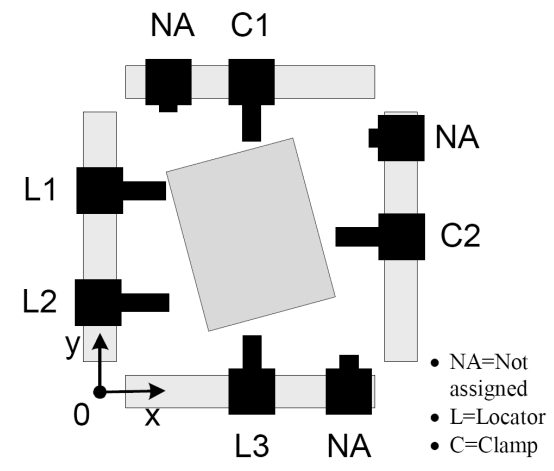

(b) Schematic concept of self-reconfigurable fixture presented in Refs [80, 81]. Source: Ref. [81], Fig. 9 .

Fig. (10): Design concepts for self-reconfigurable fixtures with the ability to reconfigure during machining process.

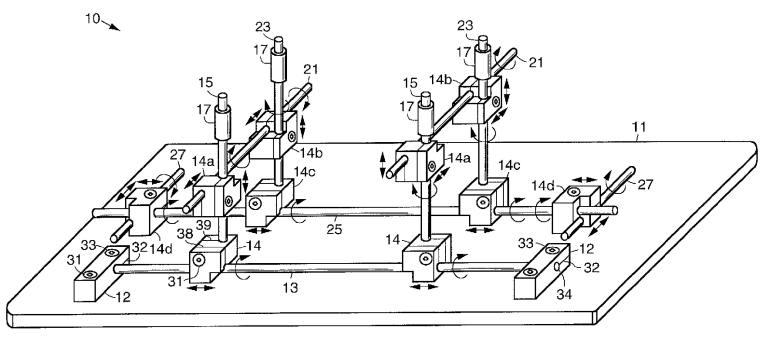

(a) Kavanaugh's 'universal holding fixture [83].

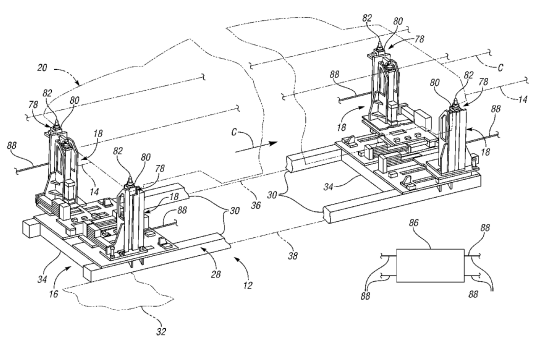

(b) Savoy's automotive assembly fixture [85]

Fig. (11): Examples of reconfigurable fixtures moving along a Cartesian Frame. 


\section{DISCUSSION}

So far, different flexible fixturing concepts have been described. It is impossible to discuss all the different concepts within the nine flexible strategies presented above; there are too many and their design is tailored to a specific category of part families or groups. Furthermore, it should be remarked here that the requirements for flexibility, turn-over times, product quality, material price, number of products and so on determine the financial investment that a manufacturer makes in flexible fixturing systems. As a result, it can be stated that all technologies are still current. The proof for this statement is that there are still many patent applications from industry for modular fixturing and fixturing automation, whereas academic research in the last few years has largely moved to automatically reconfigurable fixturing technologies.

A summary and comparison of the different fixturing technologies can be found in Tab. (1). In this table, the application of the strategy is given, and the technical capabilities are split up in level of automation provided, production size, recent patents included in this review and cost.

It can be seen that the progress of engineering, especially in actuation and sensing technology needed for mechatronics and robotics led to an advance in flexible capabilities from modular fixtures, through fixture automation and sensor-based fixture design to automatically reconfigurable fixtures and some of the adaptive concepts reviewed in Sec. 3.9.

\section{CONCLUSIONS}

Many solutions for the fixturing problem are reported in the literature. As fixture design is highly dependent on the manufacturing process and the part (compliance, machining area, reference or datum points, part dimensions), some concepts will prove to be invalid fixturing strategies under certain circumstances. Therefore, the most important conclusion is probably that there is no truly universal fixture or fixturing strategy.

Furthermore, pin-type array fixtures and phase-change fixtures yield a design with an entire different fixture layout, when compared to strategies that seek to fixture a part based on statically determined fixture layouts. External jigs are needed to locate the workpiece, and subsequently load it in these non-conventional workpiece holders.

Another important observation to make is that most fixturing solutions for flexible manufacturing, shown in Fig. (2), can be classified as prior art: Automatically reconfigurable fixtures are the youngest category of fixturing strategies, but as all strategies are still current fixturing strategies, novel concepts are still being developed within the different strategies. More recently, concepts have been developed for automatically reconfigurable fixtures. Self-reconfigurable fixtures based on PKMs and Cartesian robots have been developed. Furthermore, the more is automated in the fixture, the better it can be used in an automated environment where fixture, whether dedicated or flexible, that rely more manual tasks to load are perceived as bottleneck in production.

Additionally, it should be noted that most of the research and development work on flexible fixturing systems carried out in academia and or industry is in the areas of modular fixtures, fixturing automation, phase-change based concepts, pin-type array fixtures. For the other strategies, flexible pallet, sensor-based and chuck-based systems, less work can be found in the literature and patents. The reason for this is that these three strategies are based on flexible fixturing technologies; currently incorporated in intelligent self-reconfigurable systems; have limited application in the sense that chucks do not provide much support against lateral deformation respectively. As noted before, the fixturing of compliant parts is in many cases one of the big challenges of fixturing which explains 


\begin{tabular}{|c|c|c|}
\hline flexible fixturing concept & application & characteristics cost \\
\hline $\begin{array}{l}\text { modular fixtures and } \\
\text { flexible pallet systems }\end{array}$ & $\begin{array}{l}\text { general machining } \\
\text { and assembly }\end{array}$ & $\begin{array}{l}\text { - high turn over times, } \\
\text { - low accuracy, } \\
\text { - costs: low, but higher than a conventional dedicated fixture that can } \\
\text { fixture the same part, } \\
\text { - recent patents: [36-42]. }\end{array}$ \\
\hline fixture automation & $\begin{array}{l}\text { power workholding } \\
\text { and zero-point clamps } \\
\text { (general modular } \\
\text { fixturing components) }\end{array}$ & $\begin{array}{l}\text { - strong reduction of set-up times, } \\
\text { - step towards active fixturing systems and automation, } \\
\text { - recent patents on power workholding: Refs. [45-48], } \\
\text { - recent patents on zero-point clamps [49,50], } \\
\text { - costs: high compared to set and clamp screws. }\end{array}$ \\
\hline $\begin{array}{l}\text { sensor-based fixture de- } \\
\text { sign }\end{array}$ & $\begin{array}{l}\text { general fixture com- } \\
\text { ponents }\end{array}$ & $\begin{array}{l}\text { - sensors to augment fixturing systems for more accurate loading of } \\
\text { the fixture, } \\
\text { - first step towards active fixturing systems and automation, } \\
\text { - costs: generally sensors are expensive components. }\end{array}$ \\
\hline $\begin{array}{l}\text { phase-change based con- } \\
\text { cepts }\end{array}$ & general machining & $\begin{array}{l}\text { - very flexible form of fixturing, } \\
\text { - can fixture compliant workpieces, } \\
\text { cases as perceived drawbacks that phase-change materials are in many } \\
\text { environmental hazards, } \\
\text { - external jig or equipment needed to place part in fixture, } \\
\text { - apart from the machining areas components are submerged in the } \\
\text { phase-change material which is subsequently solidified, } \\
\text { - used to fixture parts directly or to hold pins or other fixture compo- } \\
\text { nents, } \\
\text { - costs: investment and operation costs (handling, energy etc.) rela- } \\
\text { tively high, } \\
\text { - recent patents: }[53,54] \text {. }\end{array}$ \\
\hline chuck-based concepts & $\begin{array}{l}\text { machining with low } \\
\text { forces, e.g. grinding }\end{array}$ & $\begin{array}{l}\text { - flexibility: generally, as long as workpieces have a large enough } \\
\text { flat surface they can be fixutured, some additional supports might } \\
\text { be needed, } \\
\text { - limited support restricts the applications to a low machining force } \\
\text { compared to a fixture that offers more support, } \\
\text { - as only the bottom of component is fixtured there is great accessi- } \\
\text { bility potentially reducing the number of required set ups, } \\
\text { - external jig or equipment needed to place part in fixture, } \\
\text { - costs: magnetic and vacuum chucks are widely used, so relatively } \\
\text { low to medium; other technologies found are still being developed } \\
\text { into more maturity, } \\
\text { - recent patents: }[57,58] \text {. }\end{array}$ \\
\hline pin-type array fixtures & $\begin{array}{l}\text { machining and assem- } \\
\text { bly of compliant com- } \\
\text { ponents and structures } \\
\text { (e.g. hollow turbine } \\
\text { blades, aircraft skin) }\end{array}$ & $\begin{array}{l}\text { - universality limited by size and spacing of the pins, } \\
\text { - a great number of different geometries within one group of parts } \\
\text { can be fixtured, } \\
\text { - external jig or equipment needed to place part in fixture, } \\
\text { - costs: relatively expensive due to many components, } \\
\text { - recent patents: [54,61-63]. }\end{array}$ \\
\hline $\begin{array}{l}\text { automatically reconfig- } \\
\text { urable fixtures }\end{array}$ & $\begin{array}{l}\text { general assembly } \\
\text { and machining fix- } \\
\text { tures, typically larger } \\
\text { components }\end{array}$ & $\begin{array}{l}\text { - wide range of applications, however due to costs applied in highly } \\
\text { automated large volume manufacturing such as automotive assem- } \\
\text { bly lines or potentially to ramp up production in aerospace manu- } \\
\text { facturing, } \\
\text { - loading and set-up can be highly automated, } \\
\text { - come in } 4 \text { forms: robot-built, PKM, Cartesian and gripper-based } \\
\text { systems, } \\
\text { - costs: high due to sensors and actuators, } \\
\text { - recent patents: }[46,65,66,77,82,83,85] \text {. }\end{array}$ \\
\hline other fixturing concepts & $\begin{array}{l}\text { general machining } \\
\text { fixtures }\end{array}$ & $\begin{array}{l}\text { - mostly special built as so-called adaptive fixtures, } \\
\text { - highly automated loading, unloading and set-up, } \\
\text { - costs: expensive, made to order, } \\
\text { - recent patents: [89-92]. }\end{array}$ \\
\hline
\end{tabular}

Tab. (1): Comparison of flexible fixturing strategies. 
the lower interest for research and development of chuck-based concepts.

Furthermore, a new fixturing capability is emerging from these self-reconfigurable fixturing techniques: in process reconfigurability [75] for the optimal placement of clamps and supports during the whole process time.

\section{CURRENT \& FUTURE DEVELOPMENTS}

Despite the volume of research carried out in the field of flexible automation to date, there is still much effort undertaken to create the tools, methods and technologies needed to establish automated flexible manufacturing system. These systems will rely more and more on the integration of computers and software in the design, planning and execution of the manufacturing process. Furthermore, the manufacturing processes will become more dispersed (network/cloud manufacturing). Therefore, the design of automatically reconfigurable fixturing systems and its controllers will have to be integrated with the high-level control that manages the automated production systems in the workshop. The lowlevel servo-control of intelligent fixturing systems will then have to take care of the automatic loading and unloading of a workpiece into the fixture. Furthermore, it is foreseeable that between different jobs, or even during the same job, an intelligent fixturing system can be reconfigured, requiring new low-level control settings for the clamping forces.

Currently, most of the flexible fixturing research found in the public domain is carried out by academia. A notable exception is the automotive industry, which enjoys a high level of automation. For reasons such as shorter product life-cycles costs or the shortage of skilled workers, other sectors will adopt more flexible and automated manufacturing systems. Hence, the technologies currently in use within automotive industries will diffuse to other sectors, such as aerospace, References [51, 90, 93] are some examples of this technology transfer.

For this reason, it can be expected that in the future, fixturing research will be focused on the application of mechatronics, in terms of sensory, actuation and control systems, to establish intelligent fixturing systems that have capabilities for automatic reconfiguration, automated loading and aligning of part in applications other than those in the automotive sector. A quick set-up of the fixture is paramount to reduce throughput times in the production lines. As mentioned above, power workholding by means of actuated clamps can reduce the set-up times. These actuated clamps can be used in both dedicated fixtures and a whole range of flexible fixturing system and therefore will see some further development for specific applications.

\section{ACKNOWLEDGEMENTS}

The authors wish to acknowledge: (1) the support of the European Commission through the 6th Framework Programme under Priority 3 NMP Call FP6-2004-NMP-NI-4 (AFFIX; contract number 026670); (2) the support through the funds provided in the framework of The University of Nottingham Centre for Aerospace Manufacturing, sponsored by Airbus.

\section{CONFLICT OF INTEREST}

The authors confirm that this article content has no conflicts of interest. 


\section{References}

[1] Chryssolouris G. Manufacturing Systems: Theory and Practice. 2nd ed. Mechanical Engineering Series. Springer Science and Business Media, Inc.: New York NY 2006.

[2] Bi ZM, Zhang WJ. Flexible Fixture Design and Automation: Review, Issues and Future Directions. Int J Prod Res 2001; 39(13): 2867-94.

[3] Boyle I, Rong Y, Brown DC. A Review and Analysis of Current Computer-Aided Fixture Design Approaches. Robot CIM-Int Manuf 2011; 27(1): 1-12.

[4] Cecil J. Computer-Aided Fixture Design - A Review and Future Trends. Int J Adv Manuf Tech 2001; 18(11): 790-93.

[5] Hargrove SK, Kusiak A. Computer-Aided Fixture Design: A Review. Int J Prod Res 1994; 32(4): 733-53.

[6] Kang X, Peng Q. Recent Research on Computer-Aided Fixture Planning. Recent Pat Mech Eng 2009; 2(1): 8-18.

[7] Nee AYC, Whybrew K, Senthil Kumar A. Advanced Fixture Design for FMS. Springer-Verlag: London UK, 1995.

[8] Nee AYC, Tao ZJ, Senthil Kumar A. An Advanced Treatise on Fixture Design and Planning. Series on Manufacturing Systems and Technology. World Scientific Publishing Company: Singapore SG: 2004.

[9] Rong Y, Huang SH, Hou Z. Advanced Computer-Aided Fixture Design. Elsevier Academic Press: Amsterdam NL 2005.

[10] Shirinzadeh B. Strategies for Planning and Implementation of Flexible Fixturing Systems in a Computer Integrated Manufacturing Environment. Comput Ind 1996; 30(3): 175-83.

[11] Trappey JC, Liu CR. A Literature Survey of Fixture Design Automation. Int J Adv Manuf Tech 1990; 5(3): 240-55.

[12] Wang H, Rong YK, Li H, Shaun P. Computer Aided Fixture Design: Recent Research and Trends. Comput Aided Design 2010; 42(12): 1085-94.

[13] Bakker OJ, Papastathis TN, Popov AA, Ratchev SM. Active Fixturing: Literature Review and Future Research directions. Int J Prod Res 2012; iFirst: 1-20.

[14] Dashchenko AI. Reconfigurable Manufacturing Systems and Transformable Factories. SpringerVerlag: Berlin Heidelberg D 2006.

[15] Hazen BF, Wright PK. Workholding Automation: Innovations in Analysis, Design, and Planning. Manuf Review 1990; 3(4): 224-36.

[16] Shirinzadeh B. Flexible and Automated Workholding Systems. Ind Robot 1995; 22(2): 29-34.

[17] Kals HJJ, van Luttervelt CA, Moulijn KA. Industriële Productie, Het Voortbrengen van Mechanische Producten $\{\sim$ Industrial Production, The Manufacturing of Mechanical Products\}. 2nd ed. (In Dutch) Wegener Tijdschriften Groep: Diemen NL 1998. 
[18] Whitney DE. Mechanical Assemeblies, Their Design, Manufacture, and Role in Product Development. Oxford Series on Advanced Manufacturing. Oxford University Press: Oxford UK 2004.

[19] Xiong C, Ding H, Xiong Y. Fundamentals of Robotic Grasping and Fixturing. Series on Manufacturing Systems and Technology. World Scientific Publishing Company: Singapore SG 2007.

[20] Daimon M, Yoshida T, Kojima N, Yamamoto H, Hoshi T. Study for Designing Fixtures Considering Dynamics of Thin-Walled Plate- and Box-Like Workpieces. CIRP Ann - Manuf Tech 1985; 34(1): 319-22.

[21] Deiab IM. On the Effect of Fixture layout on Part Stability and Flatness During Machining: A Finite Element Analysis. Proc IMechE Part B: J Eng Manuf 2006; 220(10): 1613-20.

[22] Ceglarek D, Li HF, Tang Y. Modeling and Optimization of End Effector Layout for Handling Compliant Sheet Metal Parts. Trans ASME - J Manuf Sci Eng 2001; 123(3): 473-80.

[23] Leopold J. Clamping Modeling - State-of-the-Art and Future Trends. In: Xiong C, Liu H, Huang Y Y Xiong, editors. Intelligent Robotics and Applications. vol. 5315/2008 of Lecture Notes in Computer Science. ICIRA 2008, Wuhan, China, October 15-17, 2008 Proceedings, Part II. Springer-Verlag: Berlin Heidelberg D 2008. p. 289-300.

[24] Liao YG, Hu SJ. An Integrated Model of a Fixture-Workpiece System for Surface Quality Prediction. Int J Adv Manuf Tech 2001; 17(11): 810-18.

[25] Ramesh R, Mannan MA, Poo AN. Error Compensation in Machine Tools - A Review Part I: Geometric, Cutting-Force Induced and Fixture Dependent Errors. Int J Mach Tool Manu 2000; 40(9): 1235-56.

[26] Wang YF, Fuh JYH, Wong YS. A Model-Based Online Control of Optimal Fixturing Process. In: Proceedings of the 1997 IEEE International Conference on Robotics and Automation. IEEE: Albuquerque NM 1997. p. 2019-24.

[27] Qin G, Zhang W, Wu Z, Wan M. Systematic Modeling of Workpiece-Fixture Geometric Default and Compliance for the Prediction of Workpiece Machining Error. Trans ASME - J Manuf Sci Eng 2007; 129(4): 789-801.

[28] Kleinwinkel JW, Lenselink W, van den Bosch R, van de Put J, Kousbroek R, van Ackooy P, et al. Toepassen van Slimme Opspanmiddelen $\{\sim$ Application of Smart Fixturing $\}$. FME-CMW \{ Dutch Trade Association for Manufacturing, Metal and Electronic Industry\} (TI.06.30; In Dutch): Zoetermeer NL 2006.

[29] Marin RA, Ferreira PM. Analysis of the Influence of Fixture Locator Errors on the Compliance of Work Part Features to Geometric Tolerance Specifications. Trans ASME - J Manuf Sci Eng 2003; 125(3): 606-16.

[30] Rong Y, Hu Y W Kang, Zhang Y, Yen DW. Locating Error Analysis and Tolerance Assignment for Computer-Aided Fixture Design. Int J Prod Res. 2001; 39(15): 3529-45.

[31] Kang Y, Rong Y, Yang JC. Computer-Aided Fixture Design Verification. Part 2. Tolerance Analysis. Int J Adv Manuf Tech 2003; 21(10-11): 836-41. 
[32] Wang Y. A Methodology of Fixture Evaluation, Analysis and Optimisation. PhD Dissertation, The University of Nottingham, Nottingham UK, 2004.

[33] Cuypers W, Van Gestel N, Voet A, Kruth JP, Mingneau J, Bleys P. Optical Measurement Techniques for Mobile and Large-Scale Dimensional Metrology. Opt Laser Eng 2009; 47(3-4): 292300 .

[34] Wang Y, Wang Z, Gindy N. Collision-Free Machining Fixture Space Design Based on Parametric Tool Space for Five-Axis Grinding. Int J Adv Manuf Tech 2009; 45(1-2): 1-7.

[35] Li Q. Virtual Reality for Fixture Design and Assembly. PhD Dissertation, The University of Nottingham, Nottingham UK, October 2008.

[36] Ossbahr G. System for Joining Beams with Square or Rectangular Cross-Sections US20060228175 (2006).

[37] Kniss JM, Goff MJ, Berendt J, Micallef R. Geometric End Effector System. US7609020 (2009).

[38] Olsson B, Olsson C, Olsson M. Device for Adjustment Points of Measuring. WO2009128778 (2009).

[39] Olsson B. Space Frame Construction System. US20040194411 (2004).

[40] Ambrosi T. Device for Fastening Objects Intended to Be Measured of Worked with Accuracy. WO2004072492 (2004).

[41] Almerino C. Modular Structure Particularly for Mounting Blanks on Retainers. EP1346794 (2008).

[42] Marino PW. Grid Bar for Modular Fixturing. USD563768S (2008).

[43] Witte H. Element and System for Producing Devices for Gripping Workpieces. WO2008148772 (2008).

[44] Witte H. Strut or Receiving Part Having a Rectangular Cross-Section for a System for Constructing Devices for Clamping Workpieces. US7364146 (2008).

[45] Ring JR, Liegakos JR, Kirykowicz RR, Grzyb JS. Machining Fixture with Self-Contained Hydraulics. US8028976 (2011).

[46] Kramarczyk MA, Jones GL, Bartos AL, Lin YT, Bojda PA. Machining Fixture with SelfContained Hydraulics. US6712348 (2004).

[47] Lin YT. Adjustable Hydraulic Support Cylinder. US7637201 (2009).

[48] Stephens GA, Claxton A, Claxton D, Thompson T. Rotary Reciprocating Intensified Hydraulic Actuator. US8070463 (2011).

[49] Sandmeier B. Clamping Fixture Including a Chuck and a Workpiece Pallet Releasably Located Thereon. US8152151 (2012).

[50] Stark E. Quick Action Clamping Cylinder with a Simplified Structure. US20100219574 (2010). 
[51] Bakker OJ, Jayaweera N, Martin O, Turnock A, Helgosson P, Smith T, et al. Fixturing and Tooling for Wing Assembly with Reconfigurable Datum System Pickup. In: SAE 2011 AeroTech Congress \& Exhibition paper 2011-01-2556. SAE: Toulouse F, October, 2011. p. 1-8.

[52] Benhabib B, Chan KC, Dai MQ. A Modular Programmable Fixturing System. Trans ASME - J Eng Ind 1991; 113(1): 93-100.

[53] Zhang X. Magnetorheological Fluids Workpiece Holding Apparatus and Method. US6267364 (2001).

[54] Sears IG, Stevenson R, Menassa RL. Magnetorheological Reconfigurable Clamp for a Flexible Manufacturing System. US7204481 (2007).

[55] Phuah HL. Part-Fixture Behaviour Prediction Methodology for Fixture Design Verification. PhD Dissertation, The University of Nottingham, Nottingham UK, 2005.

[56] Meshreki M, Kövecses J, Attia H, Tounsi N. Dynamics Modeling and Analysis of Thin-Walled Aerospace Structures for Fixture Design in Multiaxis Milling. Trans ASME - J Manuf Sci Eng 2008; 130(3): 031011-1-031011-12.

[57] De Meter EC. Light Activated Adhesive Gripper (LAAG) Workholding Technology and Process. J Manuf Proc 2004; 6(2): 201-14.

[58] DeMeter EC, Powell RM. Fixture and Method of Holding and Debonding a Workpiece with the Fixture. US7524390 (2008).

[59] Munro C, Walczyk DF. Reconfigurable Pin-Type Tooling: A Survey of Prior Art and Reduction to Practice. Trans ASME - J Manuf Sci Eng 2007; 129(3): 551-65.

[60] Walczyk DF, Longtin RS. Fixturing of Compliant Parts Using a Matrix of Reconfigurable Pins. Trans ASME - J Manuf Sci Eng 2000; 122(4): 766-72.

[61] Halford BJ. Reconfigurable Workpiece Support. 7901166 (2011).

[62] Beecherl PM, Szuba PS, Manjunathaiah J, McGaffey KJ, Crelley FP, Melkote SN. Flexible Fixturing Apparatus. US20040026842 (2004).

[63] Gindy N, Fahmi A, Wang Y, Kancharla VS, Walker K. Engagement Arrangement. US20110272537 (2011).

[64] Shen CH, Lin YT, Agapiou JS, Jones GL, Kramarczyk MA, Bandyopadhyay P. An Innovative Reconfigurable and Totally Automated Fixture System for Agile Manufacturing Applications. Trans NAMRI/SME 2003; 31: 325-402.

[65] Shen CH, Lin YT, Agapiou JS, Bojda PA, Jones GL, Spicer JP. Reconfigurable Workholding Fixture. US6644637 (2003).

[66] Lin YT, Kramarczyk MA, Jones GL, Bartos AL, Bojda PA, Shen CH, et al.. Reconfigurable Workholding Fixture. US6877729 (2005).

[67] Sudsang A, Ponce J, Srinivasa N. Grasping and In-Hand Manipulation: Geometry and Algorithms. Algorithmica 2000; 26(3-4): 466-93. 
[68] Chan KC, Lin CS. Development of a Computer Numerical Control (CNC) Modular FixtureMachine Design of a Standard Multifinger Module. Int J Adv Manuf Tech 1996; 11(1): 18-26.

[69] Kong Z, Ceglarek D. Fixture Workspace Synthesis for Reconfigurable Assembly Using Procrustes-Based Pairwise Configuration Optimization. J Manuf Sys 2006; 25(1): 25-38.

[70] Kurz K, Craig K, Wolf B, Stolfi F. Developing a Flexible Automated Fixturing Device. Mech Eng 1994; 116(7): 59-63.

[71] Arzanpour S, Fung J, Mills JK, Cleghorn WL. Flexible Fixture Design with Applications to Assembly of Sheet Metal Automotive Body Parts. Assembly Automation 2006; 26(2): 143-53.

[72] Wagner R, Zhuang Y, , Goldberg K. Fixturing Faceted Parts with Seven Modular Struts. In: 1995 IEEE International Symposium on Assembly and Task Planning. IEEE: Pittsburgh, PA, August, 1995. p. 133-39.

[73] Jonsson M, Kihlman H, Ossbahr G. Coordinate Controlled Fixturing for Affordable Reconfigurable Tooling. In: Proceedings of the 2nd CIRP Conference on Assembly Technologies and Systems. Toronto, Canada, September 2008. p. 1-11.

[74] Bi ZM, Lang SYT, Verner M, Orban P. Development of Reconfigurable Machines. Int J Adv Manuf Tech 2008; 39(11-12): 1227-51.

[75] Molfino R, Zoppi M, Zlatanov D. Reconfigurable Swarm Fixtures. In: Dai JS, Zoppi M, Kong X, editors. Proceedings of the ASME/IFToMM International Conference on Reconfigurable Mechanisms and Robots. London: IEEE; 2009. p. 730-735.

[76] Fleischer J, Denkena B, Winfough B, Mori M. Workpiece and Tool Handling in Metal Cutting Machines. Ann CIRP 2006; 55(2): 817-39.

[77] Akeel HA. Programmable Positioner for the Stress-Free Assembly of Assemblies. US6425177 (2004).

[78] Tol UA. Design of a Mechanically Adaptable Locating and Supporting System for an Intelligent Fixture. MSc Dissertation, University of Florida, Gainesville, FL; 2003.

[79] Madden JJ. Welding Fixture with Active Position Adapting Functions. BSc Dissertation, Worcester Polytechnic Institute, Worcester, MA, 2007.

[80] Ryll M, Papastathis TN, Ratchev S. Towards an Intelligent Fixturing System with Rapid Reconfiguration and Part Positioning. J Mater Process Tech 2008; 201(1-3): 198-203.

[81] Papastathis T, Ryll M, Ratchev S. Rapid Reconfiguration and Part Repositioning with an Intelligent Fixturing System. In: Proceedings of the 2007 International Manufacturing Science and Engineering Conference. MSEC2007-31036. ASME: Atlanta, GA, October, 2007.

[82] Clark SL. Adjustable Workpiece Positioning and Clamping System. US8104754 (2012).

[83] Kavanaugh CJ. Universal Holding Fixture. US20030034602 (2003).

[84] Anonymous. Intelligent Robots Take the Tooling out of Nissan's Sunderland Floor Pan Assembly Operation. Ind Robot: Int J 2006; 33(5): Mini feature. 
[85] Savoy MA. Assembly Line Vehicle Body Positioning. US7469473 (2008).

[86] Du H, Lin GCI. Development of an Automated Flexible Fixture for Planar Objects. Robot CIM-Int Manuf 1998; 14(3): 173-83.

[87] Chakraborty D, De Meter EC, Szuba PS. Part Location Algorithm for an Intelligent Fixturing System Part 1: System Description and Algorithm Development. J Manuf Sys 2001; 20(2): 124-34.

[88] Chakraborty D, De Meter EC, Szuba PS. Part Location Algorithm for an Intelligent Fixturing System Part 2: Algorithm Testing and Evaluation. J Manuf Sys 2001; 20(2): 135-48.

[89] Szuba PS. Intelligent Fixturing System. US6094793 (2000).

[90] Sturm Jr AJ, Rieckenberg WJ, Weniger RJ. Flexible Fixture. US7444742 (2008).

[91] Koczera R. Workholding Devices. US20120060354 (2012).

[92] Koczera R. Part Fixturing Systems Having Expanding Clamping Devices. US20120061896 (2012).

[93] Jayaweera N, Bakker OJ, Smith T, Popov A, Ratchev S, Turnock A, et al. Flexible Tooling for Wing Box Rib Clamping and Drilling. In: SAE 2011 AeroTech Congress \& Exhibition paper 2011-01-2639. SAE: Toulouse F, October, 2011. p. 1-9. 